\title{
Prevalence of Gestational Malaria in Kisangani, Democratic Republic of Congo
}

\author{
Noël Labama Otuli' ${ }^{1}$ Jean-Didier Bosenge Nguma1, Maindo A. Mike-Antoine ${ }^{1}$, \\ Antoine Modia 0'yandjo', Gedeon Katenga Bosunga', Joris Losimba Likwela², \\ Jean-Pascal Manga Okenge ${ }^{1}$
}

\footnotetext{
${ }^{1}$ Department of Gynecology and Obstetrics, Faculty of Medicine and Pharmacy, University of Kisangani, Kisangani, Democratic Republic of the Congo

${ }^{2}$ Department of Public Health, Faculty of Medicine and Pharmacy, University of Kisangani, Kisangani, Democratic Republic of the Congo

Email: jdidier.bosenge@unikis.ac.cd
}

How to cite this paper: Labama Otuli, N., Bosenge Nguma, J.-D., Mike-Antoine, M.A., Modia O'yandjo, A., Katenga Bosunga, G., Losimba Likwela, J. and Manga Okenge, J.-P. (2018) Prevalence of Gestational Malaria in Kisangani, Democratic Republic of Congo. Open Journal of Obstetrics and Gynecology, 8, 854-866.

https://doi.org/10.4236/ojog.2018.810089

Received: July 11, 2018

Accepted: August 21, 2018

Published: August 24, 2018

Copyright (c) 2018 by authors and Scientific Research Publishing Inc. This work is licensed under the Creative Commons Attribution International License (CC BY 4.0).

http://creativecommons.org/licenses/by/4.0/

\section{(c) (†) Open Access}

\begin{abstract}
Introduction: Gestational malaria is a major public health problem because it is a threat to pregnant women and their children. As Kisangani is a stable malaria transmission area and there is a paucity of data on the status of gestational malaria in our settings, we have found it appropriate to determine the prevalence of gestational malaria and its determinants in Kisangani City. Methods: We conducted a cross-sectional analytical study in Kisangani from January 1 to September 30, 2017. Our population study consisted of 1248 parturients recruited at delivery. We made the thick drop in peripheral blood from parturients at the admission and at the level of placental impressions after delivery. Results: The average age of the respondents was $25.3971 \pm$ 6.2452 years; the overall prevalence of gestational malaria was $27.56 \%$ including $12.66 \%$ peripheral parasitaemia, $12.34 \%$ placental parasitaemia and $2.56 \%$ parasitaemia level and placental and peripheral blood impressions. Youngest age $\leq 18$ years [OR $(95 \% \mathrm{CI})=2.44(1.75-3.41), \mathrm{p}<0.001]$, primiparity [OR $(95 \% \mathrm{CI})=2.94(2.00-4.32), \mathrm{p}<0.001]$ and positive HIV serology [OR $(95 \% \mathrm{CI})=3.01(1.23-7.43), \mathrm{p}=0.008]$ increased the risk of gestational malaria; the use of mosquito net impregnated with insecticide [OR (95\% CI) $=0.29(0.14-0.61), \mathrm{p}<0.001]$ reduced this risk. Conclusion: The prevalence of gestational malaria is $27.56 \%$ in Kisangani. The youngest age $\leq 18$ years, the primiparity and positive HIV serology of pregnant women were the most associated risk factors.
\end{abstract}

\section{Keywords}

Gestational Malaria, Thick Drop, Placental Imprint, Parasitaemia, Kisangani 


\section{Introduction}

Malaria, known since ancient times, remains a public health problem. At the global level, in 2010 the population likely to be infected with the parasite and develop the disease was 3.2 billion, and the risk was high (more than 1 out of 1000 to contract malaria during one year) for 1.2 billion people [1].

After an unprecedented period of success in the global fight against malaria, the WHO reports that progress has stalled since 2014, and the evolution of malaria-related mortality is similar. In 2016, 216 million cases of malaria were reported in a total of 91 countries, an increase of 5 million over the previous year. The number of associated deaths reached 445,000, almost as in 2015 [2].

According to WHO, the African region still accounts for $90 \%$ of malaria cases and associated deaths worldwide [2]. Children under 5 and pregnant women are the main victims [3] [4]. Each year in Africa, more than 30 million pregnant women live in malaria endemic areas. The prevalence of malaria during pregnancy is variable in endemic areas. It varies from $5 \%$ to $40 \%$ depending on the country [5]. Malaria infestation of pregnant women is a major public health problem, as this disease is a threat to themselves and their children, with up to 200,000 newborn deaths each year due to the presence of malaria during pregnancy [6] [7].

The Democratic Republic of Congo (DRC) is the second most affected sub-Saharan African country after. These two countries alone, added to India, also account for $40 \%$ of malaria cases [8]. In northeastern DRC where Tshopo Province is located, malaria is the cause of consultation at $37 \%$ of all pathologies and the cause of death at 30\% [9]. The equatorial feature which dominates this province in general and the city of Kisangani in particular, the presence of Plasmodium falciparum which ensures there an intense and permanent transmission as well as the unsanitary environment would be the cause. However, there is no data on the prevalence of gestational malaria in Kisangani.

Some factors make it difficult for Kisangani to control malaria among pregnant women. According to the National Malaria Control Program of the Eastern Province (DRC), these factors include late and irregular attendance of antenatal control (ANC) by pregnant women, as well as the shortage of sulfadoxine-pyrimethmine (SP) in care structures [4].

In view of the above, we conducted this study to determine the prevalence of gestational malaria and its determinants in the city of Kisangani.

\section{Methods}

We conducted a cross-sectional analytical study in 6 medical units in Kisangani city from January 1 st to September 30th, 2017. We chose a medical training per commune, except for the commune of Makiso which had two and the commune of Kisangani which did not have any. This choice was motivated by the fact that they are first-level medical training and are very popular with pregnant women. As for the number of medical units in Makiso commune, this was due to two reasons: this commune is the commercial center of Kisangani which attracts 
many pregnant women; and the second structure retained, the Kabondo General Reference Hospital (GRH), also receives pregnant women from Kisangani commune where there are no first-level medical units.

Data collection was prospective. The survey team consisted of twelve nurses or midwives (two per medical facility) and six laboratory technicians (one per structure). These nurses or midwives had attended training sessions in order to standardize the interview procedure. Laboratory technicians were briefed on techniques for peripheral blood sampling and placental fingerprinting, spreading, and specimen routing as directed by the National Malaria Control Program.

We recruited in an exhaustive way all the parturients admitted in the medical structures selected during our period of study. To be included, these parturients should not have a history of taking antimalarial in the two weeks preceding delivery, or come from an environment other than Kisangani and its surroundings (more than $30 \mathrm{~km}$ ) for less than 14 days before delivery. Also excluded were parturients whose sample was not examined because of a poor process of spreading and those who did not consent to the study (Figure 1).

On admission to the work-room, the nurses or midwives interviewed the parturients, after informed consent for participation in the study and the investigations, to find their socio-anthropometric parameters, their antecedents and means of fight against malaria. The interview was followed by a complete physical examination of these parturients. After the physical examination, the laboratory technicians had collected a blood sample from a maternal peripheral vein and proceeded to the preparation of tick dropand thin smear. They then performed the rapid HIV test for all parturients who consented and were not screened during pregnancy. The positive test was then confirmed at the Provincial Laboratory of the national AIDS program.

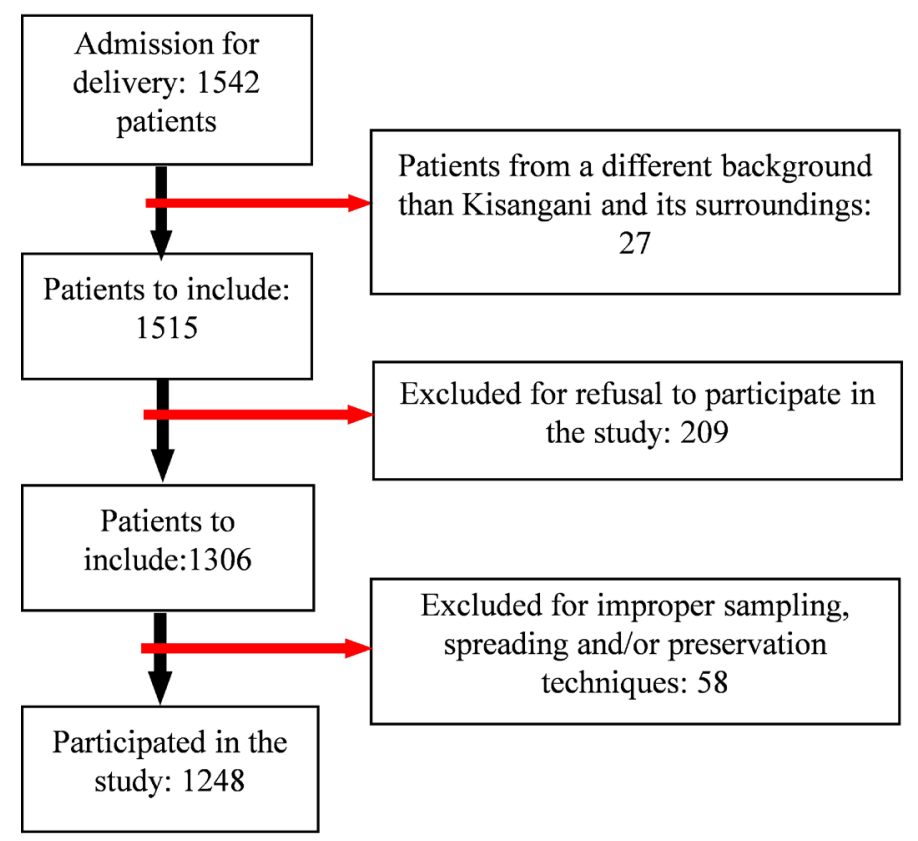

Figure 1. Flowchart. 
After delivery, laboratory technicians removed the placental imprints from the maternal side of the placenta, $1 \mathrm{~cm}$ from the umbilical cord insertion, and proceeded with the preparation of tick drop and thin smear. Reading of tick dropand thin smear was done at the Provincial Public Health Laboratory (PPHL).

For the quality-assurance of results produced by the PPHL, 125 random samples were transferred and analyzed at the national institute of biomedical research in Kinshasa. Analytical results from two laboratories were compared using Kappa's concordance analysis. In total, the agreement between the results obtained was strong $(\mathrm{k}=0.6168)$.

In our analysis, any parturient in whom tick drop was positive in the peripheral blood and/or in the placental imprint was considered a "case of gestational malaria".

The collected data were encoded in Excel and imported for analysis using Epi Info version 7.1 and Xlstat 2015 software. For the description of the sample, we calculated the frequency and the percentage as well as the averages and their standard deviations (SD). To compare proportions, we calculated Pearson's chi-squared at the significance level $\mathrm{p}<0.05$. When the Pearson chi-square application conditions were not satisfactory, we used Fisher's exact test at $<0.05$. To measure the strength of the association, we calculated the odd ratio (OR) and its $95 \%$ confidence interval (CI).

\section{Results}

\subsection{General Characteristics of the Respondents}

The mean age of our respondents was $25.40 \pm 6.24 ; 170$ respondents (13.62\%) were under 18 years of age while 128 respondents (10.26\%) were 35 or older; $25.32 \%$ of our respondents were primiparous; $24.36 \%$ were primigest; $95.03 \%$ of them used the mosquito net impregnated with insecticide (MII); the proportion of respondents with positive HIV serology was 3.37\% (Table 1).

\subsection{Prevalence of Gestational Malaria}

Of the 1248 patients included in our study, $344 \%$ or $27.56 \%$ had gestational malaria. Of these, $12.66 \%$ had a thick positive blood drop in the peripheral blood, $12.34 \%$ in the placental impressions and $2.56 \%$ in the placental impressions and in the peripheral blood.

\subsection{Gestational Malaria According to the Socio-Demographic Characteristics of Parturients}

Age of parturients was a risk factor for gestational malaria. Indeed, the youngest age $\leq 18$ years multiplied by 2.4 the risk of gestational malaria $(\mathrm{p}<0.001)$ whereas an age greater than or equal to 35 significantly reduces this risk. Educational attainment and residence did not influence this risk, whereas the informal sector as a pregnant occupation protected it from this risk [OR $(95 \% \mathrm{CI})=0.44(0.23$ $0.83) ; \mathrm{p}=0.0093$ ] (Table 2). 


\subsection{Gestational Malaria According to the History of Parturients and Means of Prevention}

With respect to the history of parturients, primiparity and primigestity were associated with an increased risk of gestational malaria of 2.94 times, respectively [OR $(95 \% \mathrm{CI})=2.94(24-3.86) ; \mathrm{p}<0.001]$ and 2.86 times [OR $(95 \% \mathrm{CI})=2.86$ (2.17 - 3.76); $\mathrm{p}<0.001]$; the same is true for HIV positive serology, which increased the risk by 3.01 [OR $(95 \% \mathrm{CI})=3.01(1.62-5.60) ; \mathrm{p}<0.001]$. On the other hand, follow-up of antenatal control (ANC) and Sulfadoxine-Pyrimethamine (SP) did not influence the risk of gestational malaria [OR $(95 \% \mathrm{CI})=0.82(0.48-1.42) ; \mathrm{p}=0.2493]$ while use of MII significantly reduced this risk [OR $(95 \% \mathrm{CI})=0.29(0.17-0.48) ; \mathrm{p}<0.001]$. The number of ANC [OR $(95 \% \mathrm{CI})=0.92(0.71-1.19) ; \mathrm{p}=0.2788]$ and the number of doses of SP [OR $(95 \% \mathrm{CI})=0.00(0.00-9.22) ; \mathrm{p}=0.5274]$ did not influence the risk of gestational malaria (Table 3).

\subsection{Maternal Fever during Labor and Gestational Malaria}

Of 26 respondents who had fever, 20 (76.92\%) had gestational malaria. Fever increased susceptibility to positive parasitaemia by 9.22 times [OR $(95 \% \mathrm{CI})=9.22$ (3.79 - 25.30); $\mathrm{p}<0.001$ ], as shown in Table 4 of our study.

Table 1. Characteristics of the respondents.

\begin{tabular}{|c|c|c|c|}
\hline Characteristics & $\begin{array}{l}\text { Frequency } \\
(\mathrm{n}=1248)\end{array}$ & Percentage & $95 \%$ CI \\
\hline \multicolumn{4}{|c|}{ Age (average $\pm \mathrm{SD}=25.3971 \pm 6.2427)$} \\
\hline$\leq 18$ & 170 & 13.62 & $11.79-15.68$ \\
\hline $19-34$ & 950 & 76.12 & $73.64-78.44$ \\
\hline$\geq 35$ & 128 & 10.26 & $8.66-12.11$ \\
\hline \multicolumn{4}{|l|}{ Level of education } \\
\hline Superior & 154 & 12.34 & $10.59-14.32$ \\
\hline Secondary & 890 & 71.31 & $68.70-73.79$ \\
\hline Primary & 174 & 13.94 & $12.09-16.02$ \\
\hline Illiterate & 30 & 2.40 & $1.66-3.46$ \\
\hline \multicolumn{4}{|l|}{ Profession } \\
\hline Pupil/student & 84 & 6.73 & $5.43-8.30$ \\
\hline whithout & 1050 & 84.13 & $81.96-86.09$ \\
\hline Salaried & 34 & 2.72 & $1.92-3.83$ \\
\hline Informal sector & 80 & 6.41 & $5.14-7.95$ \\
\hline \multicolumn{4}{|l|}{ Residence } \\
\hline Rural & 192 & 15.58 & $13.45-17.53$ \\
\hline Urban & 1056 & 84.62 & $82.47-86.55$ \\
\hline Medical structure & & & \\
\hline
\end{tabular}




\section{Continued}

\begin{tabular}{cccc}
\hline${ }^{*}$ RHC Foyer & 314 & 25.16 & $22.79-27.68$ \\
RHC Matete & 334 & 26.76 & $24.34-29.33$ \\
RHC Saint-Joseph & 178 & 14.26 & $12.39-16.35$ \\
GRH Kabondo & 202 & 16.19 & $14.21-18.37$ \\
GRH Lubunga & 128 & 10.26 & $8.66-12.11$ \\
GRH Makiso & 92 & 7.37 & $6.01-9.00$
\end{tabular}

Parity (Average $\pm \mathrm{SD}=2.0962 \pm 1.9888$ )

$\begin{array}{llll}\text { Multiparous } & 932 & 74.68 & 72.15-77.05 \\ \text { Primiparous } & 316 & 25.32 & 22.95-27.85\end{array}$

Gravidity (Average $\pm \mathrm{SD}=3.3830 \pm 2.2296$ )

$\begin{array}{llll}\text { Multigest } & 944 & 75.64 & 73.14-77.98 \\ \text { Primigest } & 304 & 24.36 & 22.02-26.86\end{array}$

ANC (Average $\pm \mathrm{SD}=3.0865 \pm 1.2614$ )

$\begin{array}{cccc}0 & 80 & 6.41 & 5.14-7.95 \\ 1 & 60 & 4.81 & 3.72-6.18 \\ 2 & 160 & 12.82 & 11.04-14.83 \\ 3 & 442 & 32.77 & 32.77-38.15 \\ 4 & 384 & 30.77 & 28.23-33.43 \\ 5 & 122 & 9.7 & 8.21-11.59\end{array}$

Doses of SP administered (Average $\pm \mathrm{SD}=2.5849 \pm 0.8528$ )

$\begin{array}{cccc}0 & 80 & 6.41 & 5.14-7.95 \\ 1 & 60 & 4.81 & 3.72-6.18 \\ 2 & 160 & 12.82 & 11.04-14.83 \\ 3 & 947 & 75.80 & 73.31-78.13 \\ 4 & 2 & 0.16 & 0.03-0.64\end{array}$

Use of MII

$\begin{array}{lccc}\text { No } & 62 & 4.97 & 3.86-6.36 \\ \text { Yes } & 1186 & 95.03 & 93.64-96.14\end{array}$

HIV serology

$\begin{array}{lccc}\text { Negative } & 1206 & 96.63 & 95.44-97.53 \\ \text { Positive } & 42 & 3.37 & 2.47-4.56\end{array}$

RHC: Reference Health Center.

Table 2. Prevalence of gestational malaria according to the socio-demographic characteristics of parturients.

\begin{tabular}{|c|c|c|c|c|}
\hline & \multicolumn{2}{|c|}{ Gestational malaria } & \multirow{2}{*}{ p-Value } & \multirow{2}{*}{ OR (95\% CI) } \\
\hline & Negative (\%) & Positive (\%) & & \\
\hline \multicolumn{5}{|l|}{ Age } \\
\hline$\leq 18$ years & $94(55.29)$ & $76(44.71)$ & $<0.001$ & $2.44(1.75-3.41)$ \\
\hline $19-34$ years & $696(73.26)$ & $254(26.74)$ & 0.2429 & $0.84(0.63-1.12)$ \\
\hline$\geq 35$ years & $114(89.06)$ & $14(10.94)$ & $<0.001$ & $0.29(0.17-0.52)$ \\
\hline
\end{tabular}




\section{Continued}

\begin{tabular}{ccccc}
\hline Level of education & & & \\
Superior & $102(66.23)$ & $52(33.77)$ & 0.0658 & $1.40(0.97-2.00)$ \\
Secondary & $654(73.48)$ & $236(26.52)$ & 0.1917 & $0.83(0.63-1.09)$ \\
Primary & $128(73.56)$ & $46(26.44)$ & 0.7197 & $0.93(0.65-1.34)$ \\
Illettrate & $20(66.67)$ & $10(33.33)$ & 0.4740 & $1.32(0.61-2.85)$ \\
& & & & \\
Profession & & & & \\
Pupil/student & $58(69.05)$ & $26(30.95)$ & 0.4717 & $1.19(0.73-1.92)$ \\
whithout & $756(72)$ & $294(28)$ & 0.4274 & $1.15(0.81-1.62)$ \\
Salaried & $22(64.71)$ & $12(35.29)$ & 0.3064 & $1.44(0.70-2.96)$ \\
Informal sector & $68(85.00)$ & $12(15.00)$ & 0.0093 & $0.44(0.23-0.83)$ \\
Residence & & & & \\
Rural & $138(71.88)$ & $54(28.12)$ & 0.4219 & $0.96(0.68-1.36)$ \\
Urban & $766(72.54)$ & $290(27.46)$ & 1 & \\
\hline
\end{tabular}

Table 3. Prevalence of gestational malaria based on history of parturients and ways to prevent malaria.

\begin{tabular}{|c|c|c|c|c|}
\hline & \multicolumn{2}{|c|}{ Gestational malaria } & \multirow{2}{*}{ OR $(95 \% \mathrm{CI})$} & \multirow{2}{*}{ p-Value } \\
\hline & Negative (\%) & Positive (\%) & & \\
\hline \multicolumn{5}{|l|}{ Parity } \\
\hline Primiparous & $174(55.06)$ & $142(44.94)$ & $2.94(2.24-3.86)$ & \multirow{2}{*}{$<0.001$} \\
\hline Multiparous & $730(78.33)$ & $202(21.67)$ & 1 & \\
\hline \multicolumn{5}{|l|}{ Gestity } \\
\hline Primigest Multigest & $168(55.26)$ & $136(44.74)$ & $2.86(2.17-3.76)$ & \multirow{2}{*}{$<0.001$} \\
\hline Primıgest Multıgest & $736(77.97)$ & $208(22.03)$ & 1 & \\
\hline \multicolumn{5}{|l|}{ ANC follow-up } \\
\hline No & $44(68.75)$ & $20(31.25)$ & $0.82(0.48-1.42)$ & \multirow{2}{*}{0.2493} \\
\hline Yes & $859(72.61)$ & $324(27.39)$ & 1 & \\
\hline \multicolumn{5}{|l|}{ Number of ANC } \\
\hline $1-3$ & $488(71.98)$ & $190(28.02)$ & $0.92(0.71-1.19)$ & \multirow[t]{2}{*}{0.2788} \\
\hline$\geq 4$ & $372(73.52)$ & $134(26.48)$ & 1 & \\
\hline \multicolumn{5}{|l|}{ Taking SP } \\
\hline No & $44(68.75)$ & $20(31.25)$ & $0.82(0.48-1.42)$ & \multirow{2}{*}{0.2493} \\
\hline Yes & $859(72.61)$ & $324(27.39)$ & 1 & \\
\hline \multicolumn{5}{|c|}{ Doses of SP administered } \\
\hline $1-3$ & $858(72.59)$ & $324(27.41)$ & $0.00(0.00-9.22)$ & \multirow{2}{*}{0.5274} \\
\hline$\geq 4$ & $2(100.00)$ & $0(0.00)$ & 1 & \\
\hline \multicolumn{5}{|l|}{ HIV serology } \\
\hline Positive & $20(47.62)$ & $22(52.38)$ & $3.01(1.62-5.60)$ & \multirow{2}{*}{$<0.001$} \\
\hline Negative & $884(73.30)$ & $322(26.70)$ & 1 & \\
\hline \multicolumn{5}{|l|}{ Use of MII } \\
\hline No & $28(45.16)$ & $34(54.84)$ & $0.29(0.17-0.48)$ & \multirow{2}{*}{$<0.001$} \\
\hline Yes & $876(73.86)$ & $310(26.14)$ & 1 & \\
\hline
\end{tabular}


Table 4. Prevalence of gestational malaria in relation to maternal fever during labor.

\begin{tabular}{ccccc}
\hline \multicolumn{5}{c}{ Gestational malaria } \\
\hline Negative & Positive & \\
Maternal fever & Frequency (\%) & Frequency (\%) & OR (95\% CI) & p - Value \\
Non & $898(73.49 \%)$ & $324(26.51 \%)$ & 1 & \\
Oui & $6(23.08 \%)$ & $20(76.92 \%)$ & $9.22(3.79-25.30)$ & $<0.001$ \\
\hline
\end{tabular}

\section{Discussion}

\subsection{Prevalence of Gestational Malaria}

In this study, the overall prevalence of gestational malaria in Kisangani was $27.56 \%$. This prevalence is higher than those found by Filbert et al. [10] in Tanzania $(19.49 \%, 95 \% \mathrm{CI}=15.73-23.24)$ and by Olga et al. [11] in northwestern Colombia (9.1). It is also higher than the figure found by Lukuka et al. [12] (21\%) in four maternity hospitals in the city of Kinshasa in the DRC in 2005. It is however lower than that found by Omolola et al. [13] in Nigeria.

Parasitaemia in peripheral blood was positive in $15.22 \%$ of cases in our series. In India, Davidson et al. [14] found that among women who gave birth, 1.7 (12/717) had peripheral parasitaemia. Neeru et al. [15], Judith et al. [16] and Valérie Briand et al. [17] found peripheral parasitaemia of 2.8\% in Bastar, 5.6\% in Cameroonian parturients and 5.9\% in southern Laos, respectively.

The proportion of patients with peripheral parasitaemia was $25.8 \%$ in rural Burkina Faso [18], 27\% in Uganda [19] and 29.7\% in Geita district (northwestern Uganda, Tanzania) [10]. Parasitaemia in placental impressions was positive in $14.90 \%$ of cases. Davidson et al. [14] had found 2.4\% of cases, Olga et al. [11] $3.3 \%$ of cases; Sanata et al. [18] $4.7 \%$ of cases.

The prevalence found in our study is however lower than those found by Judith et al. [16] (25.5\%), Filbert et al. [10] (37.6\%) and Ifeanyichukwu et al. [20] (69.6\%).

We believe that the high prevalence of gestational malaria in our country is due to the fact that we are in a stable transmission zone of plasmodium. The difference with the study conducted in Kinshasa by Lukuka et al. [12] is due to the fact that Kinshasa has a lower rainfall than Kisangani. Similarly, the 2013-2014 Demographic and Health Surveys reported that prevalence is higher in Eastern Province than in Kinshasa [21]. In addition, this stability in plasmodium transmission explains the high proportion of placental parasitaemia in our series, compared to areas of unstable transmission.

\subsection{Prevalence of Gestational Malaria According to Socio-Demographic Characteristics of Parturients \\ - Age of parturients}

We found that the youngest age $\leq 18$ years was one of the risk factors for gestational malaria $(\mathrm{P}<0.000)$ while an age greater than or equal to 35 years significantly reduced this risk. This result is consistent with those of Samia et al. [22] 
[OR $(95 \% \mathrm{CI})=3.2(1.9-5.5) ; \mathrm{p}<0.001]$, Omolola et al. [13] (29.4 vs 27.7 years, $\mathrm{p}=0.001)$, Judith et al. [16] [OR $(95 \% \mathrm{CI})=4.61(1.47-14.70)]$ and Pierre De Beaudrap et al. [19]. In fact, gestational malaria is more prevalent among the younger parturients who have not yet acquired sufficient protection against malaria, unlike parturients over 35 years of age.

\section{- Residence}

In our series, the residence of the parturient did not influence the risk of gestational malaria [OR $(95 \% \mathrm{CI})=0.96(0.68-1.36) ; \mathrm{p}=0.4219]$. As for our study, in the study of Samia et al. [22] the residence was not associated with placental malaria in Sudanese women in Blue Nile State. On the other hand, Davidson et al. [14], Pierre De Beaudrap et al. [19] and Ifeanyichukwu et al. [20] found that rural residence was significantly associated with placental malaria.

We think that this difference would be related to the unsanitary environment. The urban areas of Kisangani are currently very dirty, mixed with rural areas, with many water collections that favor the development of Anopheles larvae.

\subsection{Gestational Malaria According to the History of Parturients and Means of Prevention}

\section{- Parity and Gestity}

This study made it possible to objectify that primiparity [OR $(95 \mathrm{CI})=2.94$ $(2.24-3.86) ; \mathrm{p}<0.001]$ or primigestity $[\mathrm{OR}(95 \mathrm{CI})=2.86(2.17-3.76) ; \mathrm{p}<$ 0.001 ] each increased by about 3 times the risk of malaria-induced pregnancy.

This joins the results of Samia et al. [22] and Mamoudou et al. [23] who had found that primiparity was the risk factor for placental malaria with respectively. Indeed, for Samia et al. [22] primiparity increased the risk of placental malaria by approximately 4-fold [OR $(95 \% \mathrm{CI})=3.9$ (2.1 - 7.6); $\mathrm{p}<0.001$ ]; for Mamoudou et al. [24] the risk was 5 times [OR $(95 \%$ CI $)=5.0(2.5$ - 9.8)]. Ifeanyichukwu et al. [20] found that placental density of Plasmodium was inversely related to parity.

As for gestationality, our result matches those of Omolola et al. [OR (95\% CI) $=2.5(1.5-4.2)$ ] [13] and Valérie Briand et al. [OR (95\% CI) = $3.17(1.32-7.61)$ ] [17] who found that primiparity increased the risk of gestational malaria. These results are explained by the phenomenon of placental sequestration of plasmodium, which is more common in primigest. Indeed, despite her premunition, her previously acquired immunity, a woman becomes susceptible to malaria infection during her first pregnancy when chondroitin sulfate A binding parasites encounter the placenta, as this parasite population has a modification of the antigenic determinants allowing it to escape the immune surveillance of the host. The latter develops the antibodies against this parasitic population only during subsequent pregnancies.

\section{- Antenatal control}

In our series, follow-up of ANC did not influence the occurrence of gestational malaria [OR $(95 \% \mathrm{CI})=0.82(0.48-1.42) ; \mathrm{p}=0.2493$ ]. This result differs from that of Neeru et al. [15] who had found a low prevalence of peripheral parasi- 
taemia among pregnant women who had followed ANC, as well as Samia et al. [22] who reported that non-attendance of ANC increased the risk of gestational malaria by almost 12 times [OR $(95 \% \mathrm{CI})=11.9(7.8-18.1) ; \mathrm{p}<0.001]$. Judith et al. [16] found a high incidence of microscopic parasitaemia at delivery in pregnant women who started third-trimester ANC and who received only one dose of SPcompared with two-dose.

- Intake and number of doses of Sulfadoxine-Pyrimethamine administered

We found that taking Sulfadoxine-Pyrimethamine did not influence the risk of gestational malaria [OR $(95 \% \mathrm{CI})=0.82(0.48-1.42) ; \mathrm{p}=0.2493$ ].

Mamoudou et al. [23] found that the use of intermittent malaria prophylaxis for SP was not associated with malarial P. falciparum infestation. In contrast, compared to women who did not receiveintermittent malaria prophylaxis, Pierre et al. [19] found that pregnant women who received one or two doses experienced a five or tenfold reduction, respectively, in the risk of malaria infection $[\operatorname{RRa}(95 \% \mathrm{CI})=0.20(0.14-0.30)$ and $0.10,(95 \% \mathrm{CI})=(0.06-0.18)]$.

In our series, the number of doses of SP [95\% OR IC $=0.00(0.00-9.22) ; \mathrm{p}=$ 0.5274 ] did not influence the risk of gestational malaria. This result does not agree with those of Filbert et al. [10], Sanata et al. [18] and Kimberly et al. [24] who reported that the prevalence of gestational malaria decreased with the number of intermittent preventive treatment doses.

We believe that MS does not provide enough protection for this series of anti-malarial drugs. This would be due to the inefficiency of this molecule or to the resistance of plasmodium.

- Use of $M I I$

In our series, the use of MII reduced the risk of gestational malaria by 0.29 [OR $(95 \% \mathrm{CI})=0.29(0.17-0.48) ; \mathrm{p}<0.001]$.

Our result matches those of Ifeanyichukwu et al. [20], Pierre et al. [19] and Samia et al. [23] [OR $(95 \% \mathrm{CI})=3.5(1.7-6.8)$; $\mathrm{p}<0.001]$. On the other hand, it is reversed by Valérie et al. [17] who reported in their study that all infected women reported sleeping under a net bed the day before the survey.

We believe that the MII remains an effective means for the prevention of gestational malaria, especially through its repellent effect. However, the time that pregnant women spend outside before sleeping under the MII exposes them to mosquito bites and that to malaria.

\section{- HIV serology}

Positive HIV serology increases 3.01 times the risk [OR $(95 \%$ CI $)=3.01(1.62$ - 5.60); $\mathrm{p}<0.001$ ]. Our result is consistent with that of Pierre et al. [19].

One of the major reasons advanced to explain the susceptibility of HIV-positive women to malaria is the cytokine-induced deregulation caused by $\mathrm{HIV}$ and the lack of protective response by IFN- $Y$. Loss of IFN- $Y$ response in HIV-positive pregnant women, especially after antigenic stimulation of $\mathrm{P}$. falciparum, may impair their ability to control malaria infection. In addition, the substantial loss of mononuclear cell production of placental intervillosities of IL-12, but not IL-18, or IFN- $Y$ inducible protein-10 (IP-10), is observed in 
women with HIV and $P$. falciparum co-infection. The consequence of this deterioration is the increase in susceptibility to malaria by pregnant women [25].

- Maternal fever during labor and gestational malaria

Fever increased 9.22 times the susceptibility to positive parasitaemia [OR $(95 \% \mathrm{CI})=9.22(3.79-25.30) ; \mathrm{p}<0.001]$. Our results corroborate those of Davidson et al. [14] and Judith et al. [16] who found that the fever increased by 5.34 times $[\mathrm{RR}(95 \% \mathrm{CI})=5.34(2.89-9.90)]$ and 2.98 times $[\mathrm{OR}(95 \% \mathrm{CI})=2.98$ (1.58 - 5.73)] the risk of detecting parasitaemia under the microscope. This justifies the fact that malaria is the most frequent febrile illness in sub-Saharan Africa.

\section{Conclusion}

The prevalence of gestational malaria in Kisangani, at $27.56 \%$, is enormous. The youngest age $\leq 18$ years, primiparity and primigestity, as well as the positive HIV status of gestants, are the determining factors. The use of MII reduces this risk. Maternal fever increases the risk of detection of parasitaemia under a microscope, hence the importance of always thinking about gestational malaria in pregnant women who have fever in our environment. The dose and number of doses of SP did not influence the risk of gestational malaria. Several reasons have been mentioned to explain this fact, in particular the possible inefficiency of this molecule or the probable resistance of the plasmodium. In order to reduce the prevalence of gestational malaria in our environment, a study comparing the efficacy of SP with that of another molecule for intermittent malaria prophylaxis should be conducted.

\section{Ethical Considerations}

Before conducting this study, the study protocol was approved by the ethics committee of Kisangani University. The special authorizations were obtained from the staff of the Department of Gyneco-Obstetrics and the Decanal Authorities of the Faculty of Medicine and Pharmacy of the University of Kisangani, and the heads of the selected medical units. Informed consent was previously obtained from pregnant women before being selected for the study. In all the pregnant women included in the study, and in whom peripheral or placental parasitaemia was positive, antimalarial treatment was administered according to the recommendations of the National Malaria Control Program in DRC

\section{Contributions of the Authors}

Dr. Labama conceived the protocol and wrote the manuscript. Doctors Labama and Bosenge were responsible for collecting the data. Doctors Bosenge and Maindo coded and processed the data and contributed to thereview of literature. Professors Modia, Katenga and Likwela had corrected the protocol and enriched the manuscript. Professor Manga had corrected the protocol, validated the research and enriched the manuscript. All authors have validated the final version 
of the manuscript.

\section{Conflict of Interest}

The authors state that they have no conflict of interest.

\section{References}

[1] World Health Organization (2011) World Malaria Report 2011. WHO, Genève.

[2] World Health Organization (2017) World Malaria Report 2017. WHO, Genève.

[3] PNLP, Ministère de la santé, RDC (2009) Programme national de lutte contre le paludisme/Province orientale, Rapport annuel 2009 des activités antipaludiques en Province orientale. PNLP, Ministère de la santé, RDC.

[4] PNLP, Ministère de la santé, RDC (2011) Programme national de lutte contre le paludisme/Province orientale, Rapport annuel 2011 des activités antipaludiques en Province orientale. PNLP, Ministère de la santé, RDC.

[5] Nosten, F., et al. (2004) Malaria in Pregnancy and the Endemicity Spectrum: What Can We Learn? TRENDS in Parasitology, 20, 425-432. https://doi.org/10.1016/j.pt.2004.06.007

[6] Holtz, T.H., et al. (2004) Use of Antenatal Care Services and Intermittent Preventive Treatment for Malaria among Pregnant Women in Blantyre District, Malawi. Tropical Medicine and International Health, 9, 77-82. https://doi.org/10.1046/j.1365-3156.2003.01170.x

[7] Haghdoosta, A.A., Alexanderb, N. and Smith, T. (2007) Maternal Malaria during Pregnancy and Infant Mortality Rate: Critical Literature Review and a New Analytical Approach. Journal of Vector Borne Diseases, 44, 98-104.

[8] PNLP, Ministère de la santé, RDC (2009) Faire reculer le paludisme, Plan stratégique 2009-2013. Programme national de lutte contre le paludisme. PNLP, Ministère de la santé, RDC.

[9] Organisation Mondiale de la Santé (2003) Le sommet d"eAbuja sur le projet Faire Reculer le Paludisme. Secrétariat du partenariat Faire Reculer le Paludisme. OMS, Genève.

[10] Mpogoro, F.J., Matovelo, D., Dosani, A., Ngallaba, S., Mugonoand, M. and Mazigo, H.D. (2014) Uptake of Intermittent Preventive Treatment with Sulphadoxine-Pyrimethamine for Malaria during Pregnancy and Pregnancy Outcomes: A Cross-Sectional Study in Geita District, North-Western Tanzania. Malaria Journal, 13, 455. https://doi.org/10.1186/1475-2875-13-455

[11] Agudelo, O., Arango, E., Maestreand, A. and Carmona-Fonseca, J. (2013) Prevalence of Gestational, Placental and Congenital Malaria in North-West Colombia. Malaria Journal, 12, 341. https://doi.org/10.1186/1475-2875-12-341

[12] Lukuka, K.A., Fumie, O.S., Mulumbu, M.R., Lokombe, B.J. and Muyembe, T.J.J. (2006) Prévalence du paludisme à l'accouchement dans quatre maternités de la ville de Kinshasa, République Démocratique du Congo. Bulletin de la Société de pathologie exotique, $99, \mathrm{xxx}-\mathrm{xxx}$.

[13] Ayoola, O.O., Whatmore, A., Balogun, W.O., Jarrett, O.O., Cruickshankand, J.K. and Clayton, P.E. (2012) Maternal Malaria Status and Metabolic Profiles in Pregnancy and in Cord Blood: Relationships with Birth Size in Nigerian Infants. Malaria Journal, 11, 75. https://doi.org/10.1186/1475-2875-11-75

[14] Hamer, D.H., Singh, M.P., Wylie, B.J., Yeboah-Antwi, K., Tuchman, J., Desai, M., 
Udhayakumar, V., Gupta, P., Brooks, M.I., Shukla, M.M., Awasthy, K., Sabin, L., MacLeod, W.B., Dashand, A.P. and Singh, N. (2009) Burden of Malaria in Pregnancy in Jharkhand State, India. Malaria Journal, 8, 210. https://doi.org/10.1186/1475-2875-8-210

[15] Singh, N., Singh, M.P., Wylie, B.J., Hussain, M., Kojo, Y.A., Shekhar, C., Sabin, L., Desai, M., Udhayakumar, V. and Hamer, D.H. (2012) Malaria Prevalence among Pregnant Women in Two Districts with Differing Endemicity in Chhattisgarh, India. Malaria Journal, 11, 274. https://doi.org/10.1186/1475-2875-11-274

[16] Anchang-Kimbi, J.K., Achidi, E.A., Nkegoum, B., Sverremark-Ekströmand, E. and Troye-Blomberg, M. (2009) Diagnostic Comparison of Malaria Infection in Peripheral Blood, Placental Blood and Placental Biopsies in Cameroonian Parturient Women. Malaria Journal, 8, 126. https://doi.org/10.1186/1475-2875-8-126

[17] Briand, V., Le Hesran, J.-Y., Mayxay, M., Newton, P.N., Bertin, G., Houzé, S., Keomany, S., Inthavong, Y., Vannavong, N. and Chindavongsa, K. (2016) Bouasy Hongvanthongand Nadine Fievet: Prevalence of Malaria in Pregnancyin Southern Laos: A Cross-Sectional Survey. Malaria Journal, 15, 436. https://doi.org/10.1186/s12936-016-1492-2

[18] Bamba, S., Séré, A., Nikiéma, R., Halidou, T., Thiéba, B., Dao, B. and Tinga, R. (2013) Guiguemdé: Traitement préventif intermittent à la sulfadoxine: Pyriméthamine du paludisme chez les femmes enceintes: Efficacité et observance dans deux hôpitaux urbains du Burkina Faso. Pan African Medical Journal, 14, 105.

[19] De Beaudrap, P., Turyakira, E., White, L.J., Nabasumba, C., Tumwebaze, B., Muehlenbachs, A., Guérin, P.J., Boum II, Y., McGreadyand, R. and Piola, P. (2013) Impact of Malaria during Pregnancy on Pregnancy Outcomes in a Ugandan Prospective Cohort with Intensive Malaria Screening and Prompt Treatment. Malaria Journal, 12, 139. https://doi.org/10.1186/1475-2875-12-139

[20] Ezebialu, I.U., Eke, A.C., Ezeagwuna, D.A., Nwachukwu, C.E., Ifediata, F. and Ezebialu, C.U. (2012) Prevalence, Pattern, and Determinants of Placental Malaria in a Population of Southeastern Nigerian Parturients. International Journal of Infectious Diseases, 16, e860-e865. https://doi.org/10.1016/j.ijid.2012.07.014

[21] RDC (2014) Ministère du plan et Suivi de la Mise en œuvre de la Révolution de la Modernité et Ministère de la Santé Publique. Enquête Démographique et de Santé (EDS-RDC) 2013-2014.

[22] Omer, S.A., Idress, H.E., Adam, I., Abdelrahim, M., Noureldein, A.N., Abdelrazig, A.M., Elhassanand, M.O. and Sulaiman, S.M. (2017) Placental Malaria and Its Effect on Pregnancy Outcomes in Sudanese Women from Blue Nile State. Malaria Journal, 16, 374. https://doi.org/10.1186/s12936-017-2028-0

[23] Cisse, M., Sangare, I., Lougue, G., Bamba, S., Bayaneand, D. and Guiguemde, R.T. (2014) Prevalence and Risk Factors for Plasmodium Falciparum Malaria in Pregnant Women Attending Antenatal Clinic in Bobo-Dioulasso (Burkina Faso). BMC Infectious Diseases, 14, 631.

[24] Mace, K.E., Chalwe, V., Katalenich, B.L., Nambozi, M., Mubikayi, L., Mulele, C.K., Wiegand, R.E., Filler, S.J., Kamuliwo, M., Craig, A.S. and Tan, K.R. (2015) Evaluation of Sulphadoxine-Pyrimethamine for Intermittent Preventive Treatment of Malaria in Pregnancy: A Retrospective Birth Outcomes Study in Mansa, Zambia. Malaria Journal, 14, 69.

[25] Fo, T.K., et al. (2004) The Burden of Co-Infection with Human Immunodeficiency Virus Type 1 and Malaria in Pregnant Women in Sub-Saharan Africa. The American Journal of Tropical Medicine and Hygiene, 71, 41-54. 